\title{
CsPI from the perianthless early-diverging Chloranthus spicatus show function on petal development in Arabidopsis thaliana
}

\author{
Kunmei Su${ }^{1 *}$, Zhenhuan $\mathrm{Li}^{1}$ and Zhiduan Chen ${ }^{2 *}$
}

\begin{abstract}
Background: In the floral ABC model, B-class genes comprised of DEFICIENS (DEF)/APETALA3 (AP3) and GLOBOSA (GLO)/PISTILLATA (PI) had been proposed to involve in second and third whorl floral organ development. However, less is known about the function of B-class genes from early-diverging angiosperms. Chloranthaceae is one of the early-diverging angiosperm families. In this study, we characterized the role of the Pl-like gene CsPI cloned from Chloranthus spicatus which have the simplest perianthless bisexual flowers.
\end{abstract}

Results: The expression profile analysis reveals high levels of CSPI mRNA in stamens in Chloranthus spicatus, with weak distribution in leaves and other floral organs. Nevertheless, CSPI rescued both stamen and petal development in Arabidopsis thaliana pi-1 mutants and caused partially conversion of sepals into petaloid organs in wild-type Arabidopsis thaliana plants. Yeast two-hybrid analysis showed that CsPI can form not only homodimers but also heterodimers with proteins encoded by Arabidopsis thaliana and Chloranthus spicatus AP3-like genes.

Conclusions: These results suggested that CSPI has an ancestral function on stamen development and that CsPI has capability to specify petal development in Arabidopsis thaliana. The finding indicates that the activity of the encoded Pl-like proteins is highly conserved between the early-diverging Chloranthus and Arabidopsis. Moreover, our results appear to suggest that B-function genes may not play a role in perianth development in Chloranthus spicatus.

Keywords: Early-diverging angiosperm; B-class gene; CsPl; Perianthless; Petal development

\section{Background}

In plants, MADS-box genes are of particular interest because of the large size of the family and the critical developmental roles the members are known to play (Theissen et al. 2000). In the model plant Arabidopsis thaliana, five classes of MADS-box genes were involved in determing the development of floral organ identity. Functions of these genes have been summarized in the ABCDE model, which holds that different A, B, C, D and $E$ class MADS-domain proteins interact to form functional "ternary" or "quartet" protein complexes that are responsible for establishing the various floral organ identities (Egea-Cortines et al. 1999; Honma and Goto 2001; Smaczniaka et al. 2012; Theissen and Saedler

\footnotetext{
*Correspondence: primer673@126.com; zhiduan@ibcas.ac.cn

'School of Environment and Chemistry Engineering, Tianjin Polytechnic University, Tianjin 300387, China

${ }^{2}$ State Key Laboratory of Systematic and Evolutionary Botany, Institute of Botany, Chinese Academy of Sciences, Xiangshan, China
}

2001). In this model, the A class genes APETALA1 (AP1) and APETALA2 (AP2) control sepal formation; A, B [APETALA3 (AP3), PISTILLATA (PI)] and E (SEPAL$L A T A 1 / 2 / 3)$ class genes together regulate petal formation; $\mathrm{B}, \mathrm{C}$ [AGAMOUS $(A G)]$ and $\mathrm{E}$ class genes control stamen formation; $\mathrm{C}$ and $\mathrm{E}$ class genes regulate carpel formation; and the D class genes SEEDSTICK (STK) are involved in ovule development (Theissen 2001; Theissen and Saedler 2001).

Numbers of MADS-box genes have already been identified in almost every group of flowering plants, including early-diverging angiosperms. These MADS-box genes involved in flower development provided convenience for further studies on the evolution of flowers. Up to now, a huge variety of inflorescence and floral morphologies are found among flowering plants. Phylogenetic studies based on morphology and genes have demonstrated that the origin and early diversification of flowers during evolution may have significantly contributed to 
the sudden occurrence of diverse angiosperms in a relatively short time span during the Early Cretaceous. Therefore, the MADS-box gene family controlling flower development in early-diverging plants gains more and more attention.

Among the early-diverging angiosperms, the ANITA groups (ANITA is the acronym of Amborella, Nymphaeaceae, Illiciales, Trimeniaceae and Austrobaileyaceae), which have undifferentiated perianth, are suggested the earliest extant angiosperms by phylogeny analysis (Hansen et al. 2007; Soltis et al. 2007a; Qiu et al. 1999; Zanis et al. 2002). Following this earliest diverging grade, Chloranthaceae is sister to the magnoliids and together this group is sister to a large clade that includes eudicots and monocots (Hansen et al. 2007; Moore et al. 2007). In fact, the family Chloranthaceae has been placed in many different positions in phylogenetic trees based on morphology and gene sequences, for example Piperales, Laurales, Magnoliales, Austrobaileyales (reviewed by Hansen et al. 2007). The family Chloranthaceae contains four extant genera (Chloranthus, Sarcandra, Ascarina, and Hedyosmum) and approximately 70 species. Each of the four extant genera has distinctive morphological: Chloranthus and Sarcandra possess the simplest bisexual flowers in angiosperms; Ascrina and Hedyosmum, however, bear the simplest unisexual flowers in angiosperms. Thus Chloranthaceae represents an interesting model with which to explore the evolution of flowers.

In the floral $\mathrm{ABC}$ model, $\mathrm{B}$-class genes comprised of DEFICIENS (DEF)/APETALA3 (AP3) and GLOBOSA (GLO)/PISTILLATA (PI) had been proposed to involve in second and third whorl organ development. In eudicots, functions of AP3-like and PI-like genes are basically conserved in petal and stamen development (for review Soltis et al. 2007b; Becker and Theissen 2003). In the core eudicot $A$. thaliana, single mutant of $A P 3$ and PI caused the homeotic transformation of petals to sepals in the second whorl and of stamens to carpels in the third whorl (Jack et al. 1992; Goto and Meyerowitz 1994). In basal eudicots Aquilegia vulgaris and Papaver somniferum (Ranunculales), B-class genes are also found to be necessary for the development of both petals and stamens (Drea et al. 2007; Kramer et al. 2007). In the basal eudicot California poppy (Eschscholzia californica), mutant of the PI-lineage gene SEI shows homeotic changes characteristic of floral homeotic B class mutants (Lange et al. 2013). In monocots, heterologous expression studies suggested that B-class genes play the same role as in eudicots, although data from heterologous expression studies are difficult to interpret (Bartlett and Specht 2010). silky1 (si1), a mutant of Zea mays AP3-like gene, shows homeotic conversions of stamens into carpels and lodicules into palea/lemma-like structures (Ambrose et al. 2000). Consistent with this, Silky1 and Zmm16
(PI-like gene of Zea mays), are also able to rescue petal development in $A$. thaliana ap3 and pi mutant, respectively (Whipple et al. 2004). The PI homologs from Agapanthus praecox and Elaeis guineensis, monocot flowers with petaloid inner perianth organs, also have been shown to rescue the pi-1 mutant of $A$. thaliana (Nakamura et al. 2005; Adam et al. 2007). These data appear to suggest that the function of B-class genes is conserved in monocots and eudicots. However, less is known about the function of B-class genes in early-diverging angiosperms. Therefore, we preferentially selected the B class genes from the earlydiverging angiosperm Chlornthus spicatus for functional analysis.

In Chlornthus spicatus, the AP3-like gene CsAP3 have been investigated through in situ hybridization expression analyses and transformation experiments. CsAP3 is exclusively expressed in male floral organs, but is not detected in the dome-shaped spike primordia, bract primordial and leaves ( $\mathrm{Li}$ et al. 2005). Only weak complementation was seen in the third floral whorl (stamen), nevertheless, no complementation was seen in the second floral whorl (petal) when CsAP3 was expressed in A. thaliana ap3-3 mutant plants (Su et al. 2008). No ectopic gainof-function in the fourth floral whorl was observed when CsAP3 was ectopically expressed in wild-type $A$. thaliana plants. However, less research work on the function of the PI-like gene from C. spicatus was reported although complete coding sequence of CsPI has already been isolated previously ( $\mathrm{Su}$ et al. 2008). Therefore, functional analysis of CSPI is necessary.

To investigate the role of the PI-like gene CsPI in floral development, the expression pattern was analyzed using quantitative real-time PCR analysis. To complement the results of the expression pattern analyses, we transformed 35S::CsPI into wild-type A. thaliana plants and 5D3::CsPI into the pi-1 mutant plants. To explore how they worked, we tested interactions of proteins by employing the yeast two-hybrid system.

\section{Methods}

\section{Plant material and RNA extraction}

C. spicatus used in our experiments were cultivated in the Botanical Garden, Institute of Botany, Chinese Academy of Sciences, Beijing. Total RNA was prepared using Trizol (Invitrogen). Then poly(A) mRNA were purified using Oligotex mRNA Mini Kit (Qiagen) and the first-strand cDNA was synthesized with Superscript III (Invitrogen) (Su et al. 2008).

\section{Vectors construction}

Full-length CsPI cDNA sequence fragment was cloned into the binary vector pCAMBIA 1301 (Cpgbiotech). Primers YCsPI and PTA were used in PCR amplification. The cauliflower mosaic virus (CaMV) 35S promoter (Benfey and 
Chua 1990) was fused to the cDNA to drive nearly ubiquitous expression of all the transgenes in a wild-type background. Furthermore, to avoid ectopic expression of these transgenes, in another series of experiments the A. thaliana AP3 promoter 5D3 was used to drive expression of the transgenes in whorls 2 and 3 of developing $A$. thaliana flowers in the pi-1 mutant background (Lamb and Irish 2003). The promoter sequence was amplified by PCR from DNA extracted from leaves of wild-type $A$. thaliana using primers in our previous studies (Su et al. 2008).

\section{A. thaliana transformation and genotyping}

The plasmid constructs were transformed into wild-type Landsberg erecta A. thaliana plants and pi-1 mutant plants respectively, by the floral dip method (Clough and Bent 1998).

Seeds of the transgenic $A$. thaliana plants were selected on solid $0.5 \times$ MS medium (Murashige and Skoog 1962) containing $50 \mathrm{mg} / \mathrm{L}$ rifampicin at $4^{\circ} \mathrm{C}$ for 2 days, and then were transferred to the greenhouse under long-day condition ( $16 \mathrm{~h}$ light $/ 8 \mathrm{~h}$ dark) at $22^{\circ} \mathrm{C}$ for 10 days. As the control, seeds of wild-type $A$. thaliana were cultured on solid $0.5 \times$ MS medium as described above. Subsequently, the wild-type and transgenic seedlings were transplanted to soil and were cultured at $22^{\circ} \mathrm{C}$ with $16 \mathrm{~h}$ light and $8 \mathrm{~h}$ dark.

Homozygous pi-1 plants were identified using a dCAPS marker, in which BspHI cuts the wild-type sequence (Lamb and Irish 2003), but the site is abolished by the pi-1 mutation. All observed phenotypes were heritable and segregated as dominant traits. Morphological analysis was performed on the $\mathrm{T} 1$ generation.

\section{Primers used in experiments}

Primers used in our experiments were all showed in Table 1.

\section{Quantitative real-time PCR analysis}

Total RNA was extracted from roots, stems, leaves, bracts, stamens and carpels of C. spicatus for expression pattern analysis of CsPI. For their constitutive and complementary expression analysis, total RNA was extracted from the inflorescences of $A$. thaliana carrying transgenic constructs. After the purification of RNA samples, first-strand cDNA was synthesized with Superscript ${ }^{\mathrm{TM}}$ III Reverse Transcriptase (Invitrogen) in a $20 \mu$ reaction volume. Each kind of sample was prepared three times as described above. Quantitative real-time PCR was performed with the iQ SYBR Green supermix (Bio-Rad) in a Rotor-gene 3000 classic real-time PCR machine (Corbett Research). PCR conditions were $15 \mathrm{~min}$ at $95^{\circ} \mathrm{C}$, followed by 40 cycles of $30 \mathrm{~s}$ at $94^{\circ} \mathrm{C}, 30 \mathrm{~s}$ at $56^{\circ} \mathrm{C}$ and $30 \mathrm{~s}$ at $72^{\circ} \mathrm{C}$. To detect the expression pattern of CsPI in C. spicatus, the
Table 1 Primers used in this paper

\begin{tabular}{|c|c|}
\hline Name of primers & Sequence of primers \\
\hline CsPIReTi-F2 & 5'-GCGTTTAAGCTACATCTTGCATC-3' \\
\hline CSPIRETI-R2 & 5'-ATGGTTCTGGTGGAAACGAAG-3' \\
\hline qActup & 5'-CGTATGAGCAAGGAGATCAC-3' \\
\hline qActdown & 5'-CACATCTGTTGGAAGGTGCT-3' \\
\hline $18 \mathrm{~S}$ primerF & 5'-CGGCTACCACATCCAAGGAA-3' \\
\hline $18 \mathrm{~S}$ primerR & 5'-TGTCACTACCTCCCCGTGTCA-3' \\
\hline AtPINde1 & 5'-GATCTCATATGGGTAGAGGAAAG-3' \\
\hline AtPINoM & 5'-TGATTGAATTCTGTTGTCCTTCCATG-3' \\
\hline YCsAP3 & 5'-CGGGCCATGGGAAGAGGAAAGATT-3' \\
\hline CSAP3NoM & 5'-TCTATCATATGTGCAGCCCTGCTAC-3' \\
\hline YCsPI & 5'-CGGGCCATGGGTCGTGGGAAGATC-3' \\
\hline CsPINoM & 5'-TGTTCGAATTCGTTAGCCCCTCTAC-3' \\
\hline AtAP3Nde1 & 5'-GATCTCATATGGCGAGAGGGAAG-3' \\
\hline AtAP3NoM & 5'-TTCATGAATTCATCAGCCCTAACAC-3' \\
\hline PIINT-2 & 5'-CCAATTTCATGATATCTAGCTCAG-3' \\
\hline $\mathrm{Pl}-1$ & 5'-TACCAGAAGTTATCTGGCAAGAAATCATCATG-3' \\
\hline PTA & 5'-CCGGATCCTCTAGAGCGGCCGC(T) $17-3^{\prime}$ \\
\hline
\end{tabular}

C. spicatus housekeeping gene $18 \mathrm{~S}$ rRNA was used to normalize the amount of the cDNAs added to the reaction. To analysis the expression of CSPI in wild-type and pi-1 mutant $A$. thaliana, the $A$. thaliana housekeeping gene $A C T I N$ was used as normalization control. Specific primer pairs were designed with the help of Beacon Designer 4 software (Premier Biosoft International). These primers include CsPIReTi-F2, CsPIRETI-R2. In each experiment, two standard curves were applied for the relative quantification of the cDNA copies. Each sample was analyzed three times to determine reproducibility.

\section{SEM observation}

All flowers collected from the transgenic wild-type A. thaliana plants were immediately fixed with FAA (formalin: acetic acid: $50 \%$ ethanol =5: 6: 89). Then these flowers were dried and coated as described previously ( $\mathrm{Xu}$ et al. 2005), and observed with a Hitachi S-800 scanning electron microscope (SEM).

\section{Yeast two-hybrid assays}

Yeast two-hybrid assays were performed using the GAL4based MATCHMAKER Two-Hybrid System (Clontech). Saccharomyces cerevisiae strain AH109, GAL4 activation domain (AD) expression vector pGADT7 and GAL4 DNA-binding domain (DNA-BD) expression vector pGBKT7 were used. Full-length cDNA of CsAP3, CsPI, were amplified with $N c o$ I restriction enzymes digest site overlapping the start codon and BamHI at the $3^{\prime}$ end. EcoRI and BamHI sites were introduced to generate 
MADS-deleted CsAP3 and CsPI, for cloning into pGADT7 and pGBKT7, respectively. All constructs were verified by restriction enzymes analyses and sequencing. The yeast strain AH109 was transformed with above constructs according to the manufacture's protocol of small-scale LiAc yeast transformation procedure. Confirmation of the transformants and interaction analyses were performed as previously described (Shan et al. 2006; Su et al. 2008). The transformants co-transformed plasmids of AP3 and PI in absence of MADS domain from A. thaliana were used as a positive control (Yang et al. 2003). The transformants containing plasmids pGADT7 and pGBKT7 were used as a negative control.

\section{Results}

\section{Expression patterns of $C s P I$ in $C$. spicatus}

In order to get a clue about the function of CsPI, mRNA accumulation was analyzed by quantitative real-time PCR. As shown in Figure 1, CsPI mRNA was absent in roots and stems. Only weak expression of CsPI was found in leaves and bracts (Figure 1). Some expression was expressed in carpels and the strongest expression was detected in stamens (Figure 1). The expressing quantity of CsPI in stamens was 3 times what in carpels. These data suggested that CsPI was expressed broadly in C. spicatus. The expression pattern is similar to those of the PI-like genes from other early-diverging angiosperms (Kim et al. 2005; Lv et al. 2012).

\section{Ectopic expression of $C s P I$ in wild-type $A$. thaliana}

To further explore the function of CsPI in floral development, we transformed wild-type A. thaliana plants with the cDNA under the control of the cauliflower mosaic virus (CaMV) $35 \mathrm{~S}$ promoter.

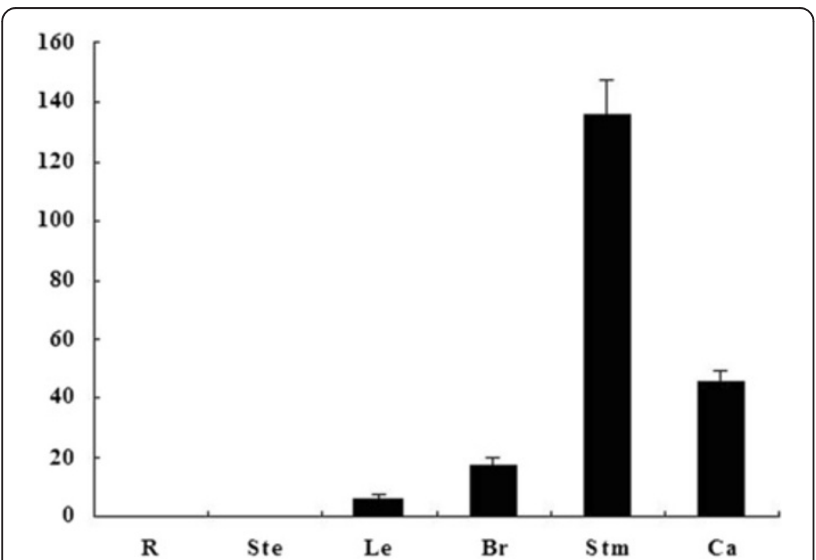

Figure 1 The detection of the expression of CsPI. Total RNAs isolated from roots (R), stems (Ste), leaves (Le), bracts (Br), stamens (Stm) and carpels (Ca) were used as templates to detect the expression of CSPI by quantitative real-time PCR. The columns represent the relative expression of these genes. Error bars represent standard deviations.
We obtained 42 A. thaliana transgenic plants, 26 of which displayed homeotic changes. The vegetative organs of these plants were normal, and no effect in flowering time was detected (data not shown). Phenotypic alterations were observed only in flowers. Flowers of these 35S::CsPI transgenic plants seemed to have two whorls of petals (Figure 2E and F). Sepals in the first whorl were partially converted into petaloid organs (Figure 2E, F, G). These petaloid structures expanded like petals although its size was smaller than that of petals (Figure 3E and F). Moreover, flowers of some 35S::CsPI transgenic plants, such as line 13 and 19 showed 5 petals and 5 petaloid sepals (Figure 2F). Noticeably different from those of the wild-type flowers, margins of these petaloid sepals consist of white tissue and surface were smooth (Figure 2F and G, compare F with A and G with $B$ separately). Examination by SEM revealed that the surface of these regions in the 35S::CsPI transgenic plants was a mosaic composed of both sepal and petal cells, while these cells were similar in shape and size (Figure $2 \mathrm{H}$, compare $\mathrm{H}$ with $\mathrm{C}, \mathrm{D}$ ). However, flowers of 35S::CsPI-3 and 35S::CsPI-25 were similar to wild-type $A$. thaliana. To find whether the severe phenotypes were correlated with CsPI expression in the transgenic plants, quantitative real-time PCR analysis was performed. Transgenic lines with only 4 petals and 4 petaloid sepals, represented by $35 \mathrm{~S}:: \mathrm{Cs} P I-5$ and $35 \mathrm{~S}:$ : CsPI-15, showed lesser RNA expression of CsPI than 35S::CsPI-13 and 35S::CsPI-19 (Figure 3). However, the expression of $C s P I$ in these 4 lines was obviously higher than what in lines 35S::CsPI-3 and 35S::CsPI-25. These data demonstrated that the accumulation levels of CsPI transcripts in different lines are consistent with phenotypic alterations.

\section{Functionality of $\mathrm{CsPI}$ in pi-1 mutants of $A$. thaliana}

In addition to the wild-type $A$. thaliana, CsPI was also transformed into $A$. thaliana pi-1 mutant plants. In this transformation experiments, the A. thaliana AP3 promoter 5D3 was used to drive expression of CsPI in whorls 2 and 3 of developing $A$. thaliana flowers in the pi-1 mutant background (Lamb and Irish 2003).

We obtained 21 independent 5D3::CsPI transgenic pi-1 plants. Among of them, 10 (47.6\%) showed full rescue and 4 (19\%) showed strong rescue. In flowers of fully rescued plants, petals had the shape of wild-type petals but were somewhat smaller (Figure 4D). Moreover, the epidermal cells of rescued petals (Figure 4I) resembled those of the wild-type which were characteristically rounded (Figure 4J). Petals of strongly rescued flowers were small and green (Figure 4C), with the epidermal petal cells which were more similar to those of wild-type petals than sepals (Figure 4H). The third-whorl floral organs of fully rescued flowers were not fully extended stamens with 

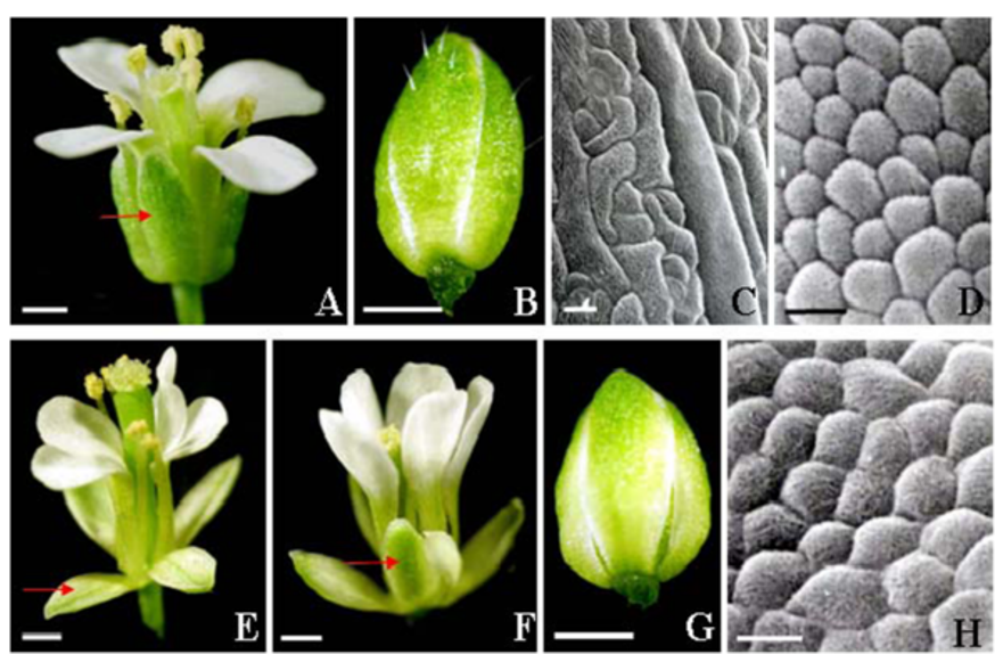

Figure 2 Overexpression of CsPI in wild-type Arabidopsis thaliana. (A-H) phenotypic analysis of transgenic Arabidopsis thaliana plants ectopically expressing CSPI. (A) Wild Arabidopsis thaliana flower, the arrow labels the first floral organ; (B) Flower bud of the wild Arabidopsis thaliana; (C) Sepal epidermis of wild Arabidopsis thaliana flower; (D) Petal epidermis of wild Arabidopsis thaliana flower. (E) Flower of 35S::CSPI transgenic lines, the arrow labels the first floral organ; (F) Flower of 35s:: CSPI transgenic lines, which have 5 petals and 5 petaloid sepals, the arrow labels the first floral organ; (G) Flower bud of the 35S:: CSPI transgenic lines; $(\mathbf{H})$ the margin epidermis of the first floral organ from 355:: $\mathrm{CsPl}$ transgenic lines. (A-B, F-G) Scale bars $=0.5 \mathrm{~mm}$; (F-I) Scale bars $=5 \mu \mathrm{m}$.

fertile pollen grains (Figure 4D), while the third floral whorl of strongly rescued flowers were mosaic organs between carpel and stamen (Figure 4E). Weak rescue was also seen for 7 (33.3\%) lines, in which neither stamens nor petals were rescued (Figure 4B).

Here, transgene expression was also determined by quantitative real-time PCR, which demonstrated that level of phenotypic rescue is correlated with the expression level of transgene (Figure 5). For example, the expression of CsPI was clearly higher in fully rescued 5D3:: CsPI-13 and 5D3::CsPI-20 than in strongly rescued 5D3::

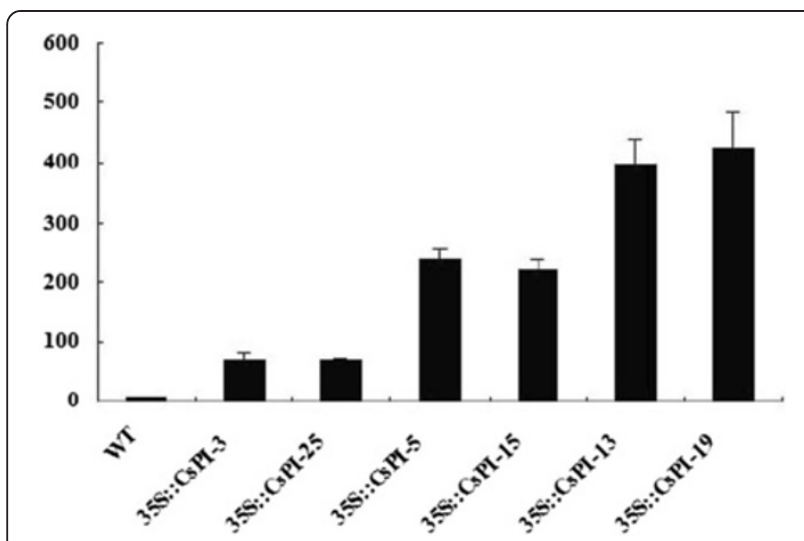

Figure 3 Detection of CsPI expressed in transgenic Arabidopsis thaliana plants through quantitative real-time PCR analysis and northern blot analysis. Samples from left to right in turn are WT (wild-type Arabidopsis thaliana), 355:: CSPI-3, 35S CsPl-25, 35S CsPl-5, 35S CsPl-15; 35S CsPl-13, 35 S CsPl-19.
CsPI-7, while the expression of CsPI was clearly lesser in weakly rescued 5D3::CsPI-2 and 5D3::CsPI-5 than in strongly rescued 5D3::CsPI-7.

\section{Interaction pattern analysis of CsPI}

To investigate the interaction patterns of CsPI proteins to learn how they worked, yeast two-hybrid assays were performed. As positive control, we investigated the interaction between A. thaliana AP3 and PI proteins, which was marked as AtAP3 and AtPI respectively. As negative controls, we detected the growth of transformants co-transformed with the fusion plasmid containing the protein and the pGADT7 or the pGBKT7 free vector.

In our experiments, interaction patterns of the fulllength and the MADS-deleted CsPI, CsAP3, AtPI and AtAP3 were tested. As negative controls, we demonstrated that transformants co-transformed with the fusion plasmid containing the protein and the pGADT7 or the pGBKT7 free vector did not grow on the selective medium (Figure $6 \mathrm{H}, \mathrm{I}$ ). As positive control, the MADSdeleted AtPI and AtAP3 sequence formed heterodimers (Figure 6) (Yang et al. 2003). Dimerization could not be observed for full-length CsPI, CsAP3, AtPI and AtAP3 (data not shown). However, the MADS-deleted CsPI can form heterodimers with AtAP3 and CsAP3 (Figure 6 A and B). Since specificity of heterodimerization is largely based on the sequence of the I-domain and K-domain (Kaufmann et al. 2005; Riechmann et al. 1996; Yang et al. 2003), this applies very likely also to the full length 

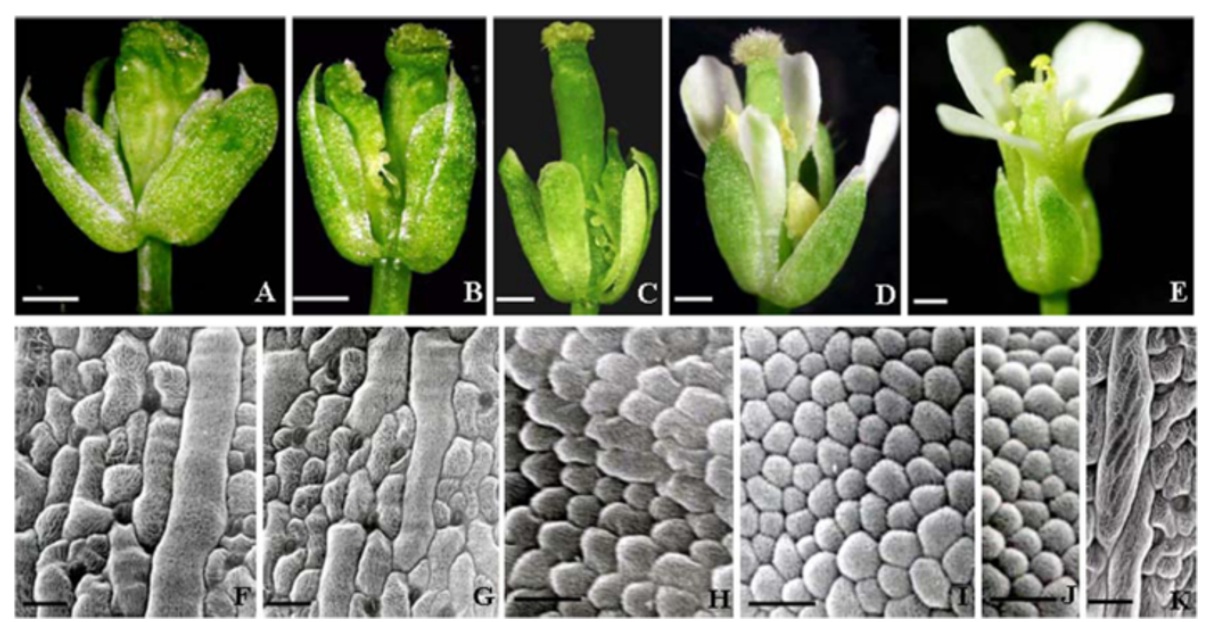

Figure 4 Calibration of the degree of rescue of transgenic flowers. (A) pi-1 mutant flower; (B-D) pi-1 homozygous mutant flowers of transgenic plants with different degrees of rescue: (B) showed weak rescue, the arrow labels the mosaic stamen, (C) strong rescue, and (D) full rescue; (E) Wild-type flower; (F) Petal epidermis of the flower shown in (A); (G) Petal epidermal cells of the flower shown in (B); (H) Petal epidermal cells of the flower shown in (C); (I) Petal epidermal cells of the flower shown in (D); (J) Petal epidermis of a wild-type Arabidopsis thaliana flower. (K) Sepal epidermis of a wild-type A. thaliana flower. Bars: (A-E) $0.5 \mathrm{~mm}$; (G-M) $10 \mu \mathrm{m}$.

(MIKC) sequence. Moreover, the MADS-deleted CsPI can also form homodimerization (Figure 6C), a feature which has been found also for some other AP3-like and PI-like proteins of non-core eudicots, including monocots such as lily (Lilium) and tulip (Tulipa), but not in core eudicots (Hsu and Yang 2002; Su et al. 2008; Tzeng et al. 2004; Winter et al. 2002). However, the MADSdeleted protein AtPI was not able to interact with itself (Figure 6G).

\section{Discussion}

According to the ABCDE model, B class genes, including both PISTILLATA (PI) and APETALA3 (AP3) homologs, contribute to petal and stamen development. Functional analysis concentrated on monocots and eudicots suggested that the function of the B-class genes is conserved. In this study, we demonstrated the functional conservation of the $P I$-like genes between the early-diverging angiosperm C. spicatus and A. thaliana.

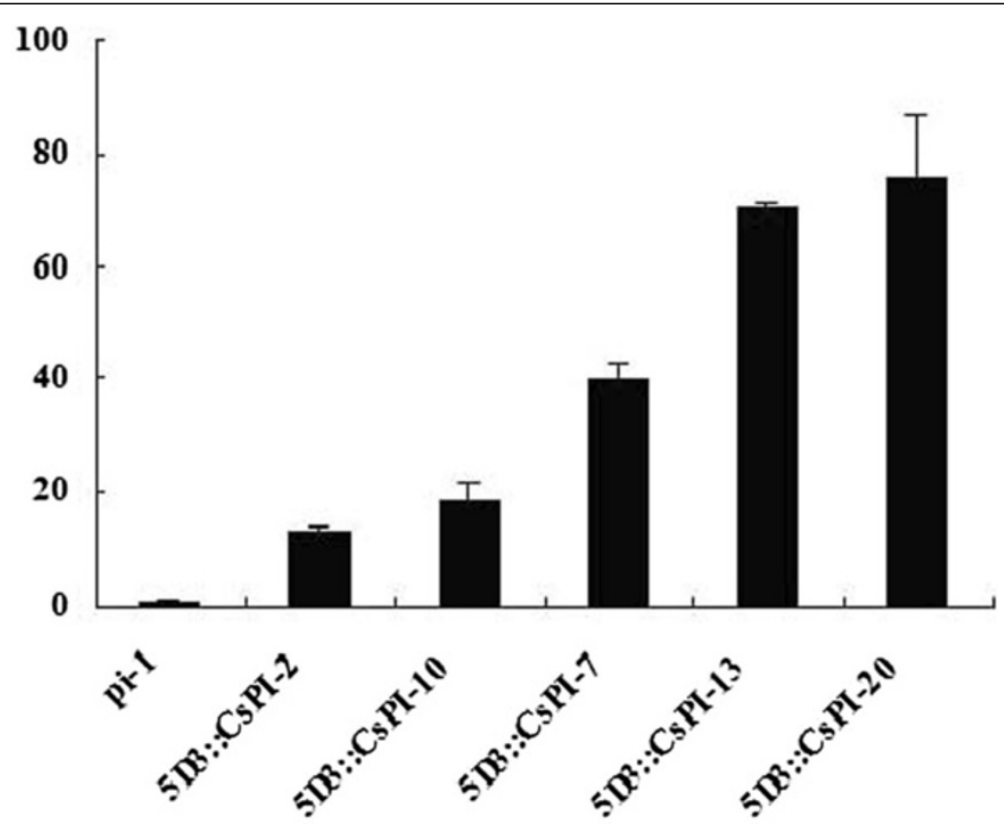

Figure 5 Detection of CsPI expressed in transgenic Arabidopsis thaliana pi-1 mutant plants through quantitative real-time PCR analysis and northern blot analysis. Samples from left to right in turn are pi-1, 5D3::CSPI-2, 5D3::CsPI-10, 5D3::CsPl-17, 5D3::CsPI-13, 5D3::CsPI-20. 


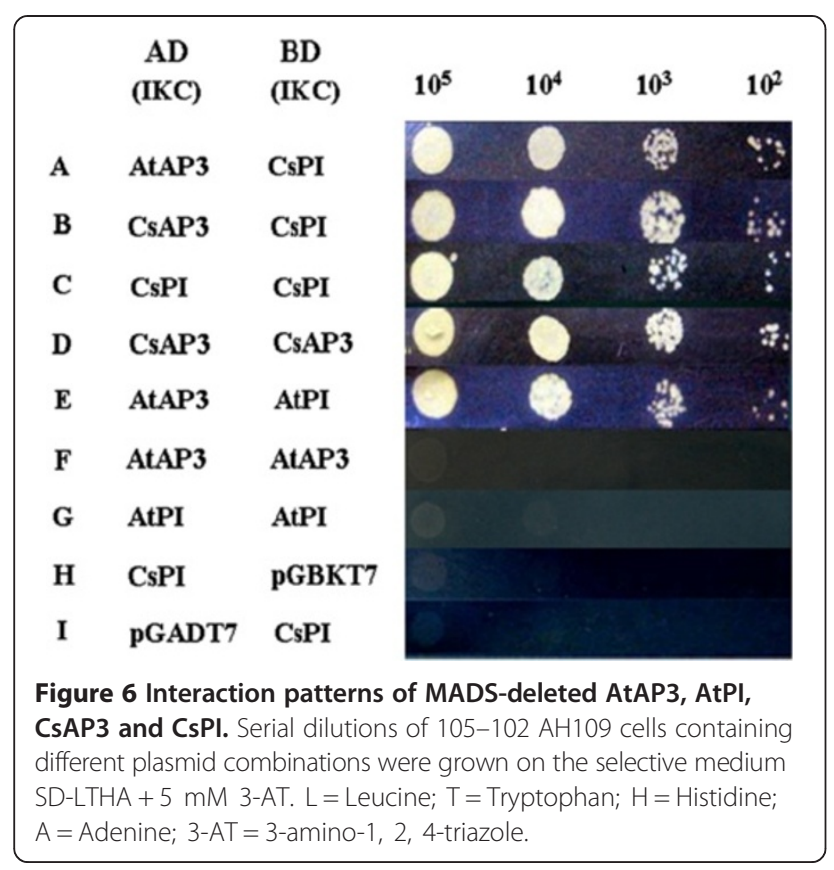

To identify the function of CsPI in C. spicatus, we detected the expression pattern through quantitative realtime PCR. CsPI was expressed in a broad range, including the leaves, bracts, stamens and carpels. The expression pattern of CsPI was different from that of the other C. spicatus B-class gene CsAP3, which was found to be exclusively expressed in stamens ( $\mathrm{Li}$ et al. 2005). The expression pattern was also different with that of the core eudicots $A P 3 / P I$ genes, which are expressed restricted to the second and third whorls (reviewed by Kim et al. 2005). However, this pattern was consistent with those of their counterparts in early-diverging angiosperms. Kim et al. also found that PI transcripts were detected in petals, stamens and carpels in early-diverging such as in Amborella trichopoda and Nuphar advena (Kim et al. 2005). Similarly, AcPI in monocot Ananas comosus was expressed in stems, leaves, bracts and sepals, petals, stamens and carpels (Lv et al. 2012). The broader range of expression of PI homologs is inferred to be the ancestral pattern for all angiosperms (Kim et al. 2005). However, it is worth mentioning that strong expression of CsPI was only detected in stamens. Although MADS-box gene function is often correlated with gene expression pattern, transient and/or weak expression does not correspond to a known genetic function (reviewed by Kim et al. 2005). Therefore, CsPI may mainly function on stamen development in C. spicatus. Compatible with this hypothesis, the complementation of the third whorl floral organs of the pi-1 mutant plants were observed when CsPI was expressed under the control of the AP3 promoter $5 D 3$. The phenotype is also observed in pi mutant plants transformed with $P I$ and the PI-like gene $Z m m 16$ from maize under the control of the A. thaliana AP3 promoter (Lamb and Irish 2003; Piwarzyk et al. 2007; Whipple et al. 2004). These results suggested that the PI-like gene CsPI from the early-diverging C. spicatus conserved the function on stamen development.

Most interestingly, CsPI also showed function on the petal development when it was expressed in wild-type or pi mutant $A$. thaliana plants. Like to those of the A. thaliana pi mutant plants expressing PI or the PIlike gene Zmm16 (Lamb and Irish 2003; Piwarzyk et al. 2007; Whipple et al. 2004; Yang et al. 2003), the second whorl floral organs were rescued when 5D3::CsPI was transformed into pi-1 mutant plants. In line with this, the 35S::CsPI transgenic plants exhibited a partial conversion of sepals to petaloid organs. This phenotype is similar to that of the 35S::PI A. thaliana plants. It has been reported that the 35S::PI A. thaliana also modifies sepals into petaloid organs but no ectopic stamen is formed (Krizek and Meyerowitz 1996; Lamb and Irish 2003; Yang et al. 2003). The only slight difference is that flowers of some $35 \mathrm{~S}:$ :CSPI plants showed an increase in the number of the first and the second floral organs. This can be attributed to the different expression levels as shown in quantitative real-time PCR analysis and northern blot analysis. Alternatively, the expression level of CsPI may be correlated with the number of petals.

As to why CsPI showed functions in A. thaliana similar to those of PI, it is possibly provided by the yeast two-hybrid analysis, which revealed that CsPI proteins can form heterodimers with AtAP3 proteins. It has been reported that the A. thaliana AtAP3 gene was faintly expressed in the first floral organ as well as in the second and the third floral organs (Jack et al. 1992; Smaczniaka et al. 2012). Therefore, the fact of transforming sepal into petalloid structures or rescue the second and the third whorl of the pi-1 mutant plants might be due to the same fact as that of the A. thaliana genes, both AP3 and PI should be present together with SEP genes (Krizek and Meyerowitz 1996).

Alternatively, homodimers of CsPI may also be able to act to specify petals with AtAP3. As shown, CsPI can form homodimers besides heterodimers. This feature also has been found for some other class B proteins of gymnosperms and non-core eudicots (Chen et al. 2012; Hsu and Yang 2002; Liu et al. 2013; Liu et al. 2010; Su et al. 2008; Tzeng et al. 2004; Winter et al. 2002; Yang et al. 2003), but not in core eudicots. For example, proteins transformed by Lilium longiflorum PI-like genes LMADS8 and LMADS9 can also form homodimers besides heterodimers (Chen et al. 2012). It's worth noting that flowers of the A. thaliana overexpressed the Lilium longiflorum LMADS8/9 (PI-like) also showed partially transformation of sepals to petaloid organs and homodimers 
of $L M A D S 8 / 9$ were able to bind to the CArG1 of AtAP3 (Chen et al. 2012). Moreover, C-terminal deleted HoPI (PI-like) proteins from Hedyosmum orientale (Chloranthaceae) lost the petal identity function in $A$. thaliana as they failed to form homodimers (Liu et al. 2013). For these facts, we can't exclude such a scenario for homodimers of CsPI to act in petal development in A. thaliana. This interaction pattern may represent an ancient flexible interaction of AP3 and PI lineage proteins (Liu et al. 2013).

This finding that CsPI has capability to specify petal identity in A. thaliana was compatible with the view that the perianthless state of $C$. spicatus is derived rather than ancestral ( $\mathrm{Li}$ et al. 2005). As to the loss of petals, we prefer the hypothesis that the $\mathrm{B}$ function,which requires the concerted expression of AP3 and PI homologues, may not contribute to petal development in Chloranthaceae (Liu et al. 2013). In $H$. orientale (Chloranthaceae), HoPI was broadly expressed in all floral organs, whereas $H o A P 3$ was restricted to stamens (Liu et al. 2013). In perianthless C. spicatus, CsPI reported here, was also broadly expressed in all floral organs, but CsAP3 was restricted to stamens (Li et al. 2005). Therefore, the overlap of AP3 and PI homologue expression is limited to the stamens in Chloranthaceae. Yet, coordinated expression of the AP3- and $P I$-like genes is correlated with the identity of petaloid organs (reviewed by Liu et al. 2013). These data appear to suggest that the main reason for the loss of petals in Chloranthaceae maybe not the floral homeotic B-function. Nonetheless, we still can't rule out the possibility that changes in cis-regulatory elements or trans-regulatory factors that regulate B-class genes are causally linked to the greatly reduced perianth in Chloranthus (Li et al. 2005). As shown in this paper, some $35 S$ ::CsPI plants showed an increase in the number of the first and the second floral organs. These plants showed expression of CsPI which was much higher than that of other plants. The data implied that weak expression of B class genes in C. spicatus may be correlated with the reduction of perianth. Consistent with this hypothesis, it has been reported that independent petal losses within buttercup family (Ranunculaceae) were strongly associated with decreased or eliminated expression of a B-class gene, APETALA3-3 (AP3-3) (Zhang et al. 2013). It would be interesting to investigate, therefore, whether there are specific cis-regulatory elements controlling the expression of CsAP3 and CsPI in petals.

\section{Conclusions}

CsPI retained the ancestral function in stamen identity and showed capability to specify petal development in A. thaliana. These data suggested that the role of $P I$-like gene was conserved in the early-diverging angiosperm Chloranthus spicatus and the core-eudicot Arabidopsis thaliana. CsPI can form homodimers besides heterodimers and they may both be involved in petal development in A. thaliana. Moreover, it seems likely that the loss of petals maybe not directly caused by the floral homeotic B-function in Chloranthus spicatus.

\section{Competing interests}

The authors declare that they have no competing interests.

\section{Authors' contributions}

KS and ZL carried out the molecular genetic studies, participated in the sequence alignment; KS and ZC drafted the manuscript. All authors read and approved the final manuscript.

\section{Acknowledgments}

The authors are grateful for the financial support of the National Natural Science Foundation of China (Nos. 30900092) and the State Key Laboratory of Systematic and Evolutionary Botany (LSEB 2012-03).

Received: 7 July 2013 Accepted: 23 December 2013 Published: 4 February 2014

\section{References}

Adam H, Jouannic S, Orieux Y, Morcillo F, Richaud F, Duval Y, Tregear JW (2007) Functional characterization of MADS box genes involved in the determination of oil palm flower structure. J Exp Bot 58:1245-1259

Ambrose BA, Lerner DR, Ciceri P, Padilla CM, Yanofsky MF, Schmidt RJ (2000) Molecular and genetic analyses of the silkyl gene reveal conservation in floral organ specification between eudicots and monocots. Mol Cell 5(3):569-579

Bartlett ME, Specht CD (2010) Evidence for the involvement of GLOBOSA-like gene duplications and expression divergence in the evolution of floral morphology in the Zingiberales. New Phytol 187:521-541

Becker A, Theissen G (2003) The major clades of MADS-box genes and their role in the development and evolution of flowering plants. Mol Phylogenet Evol 29:464-489

Benfey PN, Chua NH (1990) The cauliflower mosaic virus 355 promoter: combinatorial regulation of transcription in plants. Science 250:959-966

Chen MK, Hsieh WP, Yang CH (2012) Functional analysis reveals the possible role of the C-terminal sequences and PI motif in the function of lily (Lilium longiflorum) PISTILLATA (PI) orthologues. J Biol Chem 63:941-961

Clough SJ, Bent AF (1998) Floral dip: a simplified method for Agrobacterium-mediated transformation of Arabidopsis thaliana. Plant J 16:735-743

Drea S, Hileman LC, de Martino G, Irish VF (2007) Functional analyses of genetic pathways controlling petal specification in poppy. Development 134:4157-4166

Egea-Cortines M, Saedler H, Sommer H (1999) Ternary complex formation between the MADS-box proteins SQUAMOSA DEFICIENS and GLOBOSA is involved in the control of floral architecture in Antirrhinum maju. EMBO J 18:5370-5379

Goto K, Meyerowitz EM (1994) Function and regulation of the Arabidopsis floral homeotic gene PISTILLATA. Gene 8:1548-1560

Hansen DR, Dastidar SG, Cai ZQ, Penaflor C, Kuehl JV, Boore JL, Jansen RK (2007) Phylogenetic and evolutionary implications of complete chloroplast genome sequences of four early-diverging angiosperms: Buxus (Buxaceae), Chloranthus (Chloranthaceae), Dioscorea (Dioscoreaceae), and Illicium (Schisandraceae). Mol Phylogenet Evol 45:547-563

Honma T, Goto K (2001) Complexes of MADS-box proteins are sufficient to convert leaves into floral organs. Nature 409:525-529

Hsu HF, Yang CH (2002) An Orchid (Oncidium Gower Ramsey) AP3-like MADS gene regulates floral formation and initiation. Plant Cell Physiol 43:1198-1209

Jack T, Brockman LL, Meyerowitz EM (1992) The homeotic gene APETALA3 of Arabidopsis thaliana encodes a MADS box and is expressed in petals and stamens. Cell 68:683-697

Kaufmann K, Melzer R, Theissen G (2005) MIKC-type MADS-domain proteins: structural modularity, protein interactions and network evolution in land plants. Gene 347:183-198

Kim S, Koh J, Yoo MJ, Kong HZ, Hu Y, Ma H, Soltis PS, Soltis DE (2005) Expression of floral MADS-box genes in basal angiosperms: implications for the evolution of floral regulators. Plant J 43:724-744

Kramer EM, Holappa L, Gould B, Jaramillo MA, Setnikov D, Santiago PM (2007) Elaboration of $B$ gene function to include the identity of novel floral organs in the lower eudicot Aquilegia. Plant Cell 19:750-766 
Krizek BA, Meyerowitz EM (1996) The Arabidopsis homeotic genes APETALA3 and PISTILLATA are sufficient to provide the $B$ class organ identity function. Development 122:11-22

Lamb RS, Irish VF (2003) Functional divergence within the APETALA3/PISTILLATA floral homeotic gene lineages. Proc Natl Acad Sci U S A 100:6558-6563

Lange M, Orashakova S, Lange S, Melzer R, Theissen G, Smyth DR, Becker A (2013) The seirena B class floral homeotic mutant of California Poppy (Eschscholzia californica) reveals a function of the enigmatic PI Motif in the formation of specific multimeric MADS domain protein complexes. Plant Cell 25(2):438-453

Li GS, Meng Z, Kong HZ, Chen ZD, Theissen G, Lu AM (2005) Characterization of candidate class A, B and E floral homeotic genes from the perianthless basal angiosperm Chloranthus spicatus (Chloranthaceae). Dev Genes Evol 215:437-449

Liu CJ, Zhang J, Zhang N, Shan HY, Su KM, Zhang JS, Meng Z, Kong HZ, Chen ZD (2010) Interactions among proteins of floral MADS-Box genes in basal eudicots: implications for evolution of the regulatory network for flower development. Mol Biol Evol 27(7):1598-1611

Liu SJ, Sun YH, Du XQ, Xu QJ, Wu F, Meng Z (2013) Analysis of the APETALA3and PISTILLATA-like genes in Hedyosmum orientale (Chloranthaceae) provides insight into the evolution of the floral homeotic B-function in angiosperms. Ann Bot 112:1239-1251

Lv LL, Duan J, Xie JH, Liu YG, Wei CB, Liu SH, Zhang JX, Sun GM (2012) Cloning and expression analysis of a PISTILLATA homologous gene from pineapple (Ananas comosus L. Merr). Int J Mol Sci 13:1039-1053

Moore MJ, Bell CD, Soltis PS, Soltis DE (2007) Using plastid genome-scale data to resolve enigmatic relationships among basal angiosperms. Proc Natl Acad Sci U S A 104(49):19363-19368

Murashige T, Skoog FA (1962) Revised medium for rapid growth and bio-assays with tobacco tissue culture. Plant Physiol 15:473-497

Nakamura T, Fukuda T, Nakano M, Hasebe M, Kameya T, Kanno A (2005) The modified $A B C$ model explains the development of the petaloid perianth of Agapanthus praecox ssp. orientalis (Agapanthaceae) flowers. Plant Mol Biol 58:435-445

Piwarzyk E, Yang YZ, Jack T (2007) Conserved C-terminal motifs of the Arabidopsis proteins APETALA3 and PISTILLATA are dispensable for floral organ identity function. Plant Physiol 145(4):1495-1505

Qiu YL, Lee J, Bernasconi-Quadroni F, Soltis DE, Soltis PS, Zanis M, Zimmer EA, Chen Z, Savolainen V, Chase MW (1999) The earliest angiosperms: evidence from mitochondrial, plastid and nuclear genomes. Nature 402:404-407

Riechmann JL, Krizek BA, Meyerowitz EM (1996) Dimerization specificity of Arabidopsis MADS domain homeotic proteins APETALA1, APETALA3, PISTILLATA, and AGAMOUS. Proc Natl Acad Sci U S A 934:793-4798

Shan HY, Su KM, Lu WL, Kong HZ, Chen ZD, Meng Z (2006) Conservation and divergence of candidate class $B$ genes in Akebia trifoliata (Lardizabalaceae). Dev Genes Evol 216:785-795

Smaczniaka C, Immink RGH, Muiño JM, Blanvillain R, Busscher M, Busscher-Langeb J, Dinh QD, Liu S, Westphali AH, Boereni S, Parcy F, Xu L, Carles CC, Angenent GC, Kaufmann K (2012) Characterization of MADS-domain transcription factor complexes in Arabidopsis flower development. Proc Natl Acad Sci U S A 109(5):1560-1565

Soltis DE, Chanderbali AS, Kim S, Buzgo M, Soltis PS (2007a) The ABC model and its applicability to basal angiosperms. Ann Bot 1001:55-163

Soltis DE, Gitzendanner MA, Soltis PS (2007b) A 567-taxon data set for angiosperms: The challenges posed by bayesian analyses of large data sets. Int J Plant Sci 168(2):137-157

Su KM, Zhao SZ, Shan HY, Kong HZ, Lu WL, Theissen G, Chen ZD, Meng Z (2008) The MIK region rather than the C-terminal domain of AP3-like class B floral homeotic proteins determines functional specificity in the development and evolution of petals. New Phytol 178:544-558

Theissen G (2001) Development of floral organ identity: stories from the MADS house. Curr Opin Plant Biol 4:75-85

Theissen G, Saedler H (2001) Floral quartets. Nature 409:469-471

Theissen G, Becker A, Di Rosa A, Kanno A, Kim JT, Münster T, Winter KU, Saedler H (2000) A short history of MADS-box genes in plants. Plant Mol Biol 42:115-149

Tzeng TY, Liu HC, Yang CH (2004) The C-terminal sequence of LMADS1 is essential for the formation of homodimers for B function proteins. J Biol Chem 279:10747-10755

Whipple CJ, Ciceri P, Padilla CM, Ambrose BA, Bandong SL, Schmidt RJ (2004) Conservation of B-class floral homeotic gene function between maize and Arabidopsis. Development 131:6083-6091
Winter KU, Weiser C, Kaufmann K, Bohne A, Kirchner C, Kanno A, Saedler H, Theissen G (2002) Evolution of class B floral homeotic proteins: obligate heterodimerization originated from homodimerization. Mol Biol Evol 19:587-596

Xu YY, Wang XM, Li J, Li JH, Wu JS, Walker JC, Xu ZH, Chong K (2005) Activation of the WUS gene induces ectopic initiation of floral meristems on mature stem surface in Arabidopsis thaliana. Plant Mol Biol 57:773-784

Yang Y, Fanning L, Jack T (2003) The K domain mediates heterodimerization of the Arabidopsis floral organ identity proteins, APETALA3 and PISTILLATA. Plant J $33: 47-59$

Zanis MJ, Soltis DE, Soltis PS, Mathews S, Donoghue MJ (2002) The root of the angiosperms revisited. Proc Natl Acad Sci U S A 99:6848-6853

Zhang R, Guo CC, Zhang WG, Wang PP, Li L, Duan XS, Du QG, Zhao L, Shan HY, Hodges SA, Kramer EM, Ren Y, Kong HZ (2013) Disruption of the petal identity gene APETALA3-3 is highly correlated with loss of petals within the buttercup family (Ranunculaceae). Proc Natl Acad Sci U S A 110:5074-5079

doi:10.1186/1999-3110-55-21

Cite this article as: Su et al:: CsPI from the perianthless early-diverging Chloranthus spicatus show function on petal development in Arabidopsis thaliana. Botanical Studies 2014 55:21

\section{Submit your manuscript to a SpringerOpen ${ }^{\odot}$ journal and benefit from:}

- Convenient online submission

- Rigorous peer review

- Immediate publication on acceptance

- Open access: articles freely available online

- High visibility within the field

- Retaining the copyright to your article

Submit your next manuscript at $>$ springeropen.com 